would appear on the record-receiving surface of the new seismograph more than a foot or $30 \mathrm{~cm}$. in length. It is, of course, possible to construct a large record receiver but is it necessary? About a record of time, which is probably the most important element required by the working seismologist, nothing whatever is said.

Seismographic and other Record-receiving Surfaces.

The record receivers to which I refer are the types used in connection with horizontal pendulums adopted by the British Association, and now in use at many stations widely distributed round the world. Nearly all of these record on a surface of photographic paper moving at the rate of $60 \mathrm{~mm}$. per hour. There are, however, one or two instruments where the paper moves at a rate of about $250 \mathrm{~mm}$. per hour. With very large earthquakes, the times of commencement or the commencement of the preliminary tremors, as recorded on either the slow or comparatively rapidly moving paper, are identical, the seismographs being similar and placed side by side. With earthquakes of moderate intensity this is not always the case. On the slowly moving paper the commencement of the preliminary tremors may be lost. The explanation apparently rests in the fact that slowly moving paper passing beneath two illuminated cross slits or an illuminated "pin-hole" has a longer exposure than that which is moving quickly. The longer the exposure the broader the line. In one case the film takes about twelve seconds to pass beneath the "pinhole," and in the other between two and three seconds. of scientific investigation in the eyes of those critics who are disposed to assert that India cannot afford to be scientific.

No less than 128 pages out of the 187 which comprise the report are devoted to the reproduction of tables giving the results of magnetic observations, which are further illustrated by a map showing the stations of observation of the magnetic survey. Since the year 1901, these have been carried practically over the whole peninsular area with the exception of the Central Provinces. A description of some of the stations and of the instruments used completes the narrative, but no general deductions are made, nor is any indication afforded as to the practical result of these undoubtedly valuable observations.

Major Conyngham's report on the pendulum observations for determining the force of gravity is directly interesting. The latest instrumental equipment for this class of observation includes "half-second" pendulums, which are only one-quarter the length of those previously used in the department. A new method (an Austrian invention) has also been introduced for registration of the coincidence of beat between the free pendulum and the clock pendulum, the pendulums being no longer swung in vacuo. A considerable increase in accuracy of observation has thus been assured, further refinements being introduced in the corrections applied for the minute vibrations (or "wagging") of the stand on which the instrument is fixed, due to the swing of the pendulum. Some of the results are curious.

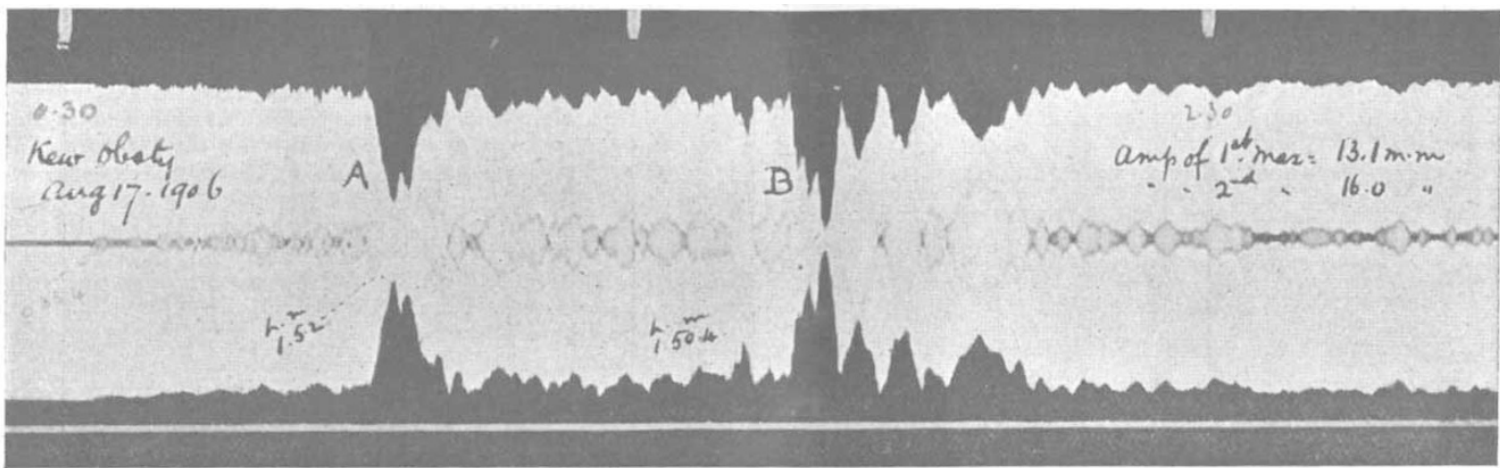

Seismogram of the Valparaiso Earthouake, August 17, 1906.

In either case, when the boom of the pendulum, which at its outer extremity carries the equivalent of a "pin-hole," is steady, we get a straight line on the film moving beneath the same. Very slight movements of the boom, however, are to be seen on the film which has passed quickly beneath its spot of light which cannot be seen on the film which has moved slowly. On the latter minute ripples have been eclipsed in the broadened line. The meaning of this, not only to practical seismologists, but to all who have to deal with photographic recording apparatus, is that the best result which can be obtained from a given instrument largely depends upon the speed of the photographic record-receiving surface.

John MiLne.

\section{SCIENCE IN INDIA.}

THE " narratives" from which extracts have been taken for publication in the report before us are those of officers of the Indian Survey Department who are employed on work of scientific investigation. There is little of topographical, and nothing of geographical, interest in them if we except certain results derived from Captain Wood's mission to Nepal. They afford, however, most convincing proof of the strenuous nature of the work of the scientific branch of the department, and should serve amply to justify the maintenance of a well-matured system

I "Extracts from Narrative Reports of Officers of the Survey of India for the Season 1903-04." Pp. 187. (Calcutta.)

NO. I 947 , VOL. 75$]$
For instance, it was found at Calcutta that the perpetual tremor, or vibration, set up by traffic, due to the nature of those alluvial deposits on which the city may be said to be floating, absolutely negatived the value of the observations, whilst, on the other hand, observations taken at Colaba, in Bombay, were not affected appreciably by the firing of the big guns of the fort in their vicinity.

The value of " $g$ " (force of gravity) being used to determine the figure of the spheroid and the density of the earth's crust, it was found at Colaba that the excess of attraction indicated by the observations equalled that which would be accounted for by a disc of earth matter below the instrument 2530 feet thick with an excess of density equal to 2.8 above the average of surface density. At Dehra Dun, on the other hand, the defect in " $g$ " indicated a deficiency in density of 2.8 extending to 2930 feet in depth. Assuming that the surface density is 2.8 , this means that we must imagine a cavity 2930 feet deep under Dehra Dun; in other words, "the matter underlying Dehra Dun is so deficient in density-we do not know to what depth this deficiency may extend-that it would have to be pressed downwards until the surface of the land was 2930 feet below its present position before it would attain the average density of the crust of the earth. Likewise at Colaba an expansion of the underlying strata until a hill 2500 feet high had been formed would be requisite to reduce the excessively dense rock that is found here to the average density of 2.8 ."

Certain levelling operations referred to in anotiner part of the report have been undertaken in the interests of these 
pendulum observations to determine the difference of level between Dehra Dun and Mussoorie.

Valuable results still continue to be obtained from the tidal observations, which extend over forty-two ports from Aden to Port Blair. Tide tables for forty ports are now published in England based on the observations of the Indian Survey. Several instructive tables will be found in the report, especially those showing the errors in the predicted times and heights of high and low water at the various stations. These tables apparently indicate a superiority in the automatic system of recording.

Amongst the most interesting records of the season are the results obtained by a careful re-computation of Captain Wood's observations for determining the position of Everest and other high peaks in Nepal. The more rigorous methods employed give a very slight difference (never amounting to half a second of arc) between the new and old determinations of the coordinate values of the stations of observation, which differences are refiected in a greater degree in the values of the peaks observed, but the corrections in altitude of the peaks observed, due to the employment of a revised coefficient for refraction, are more marked. The height of Mount Everest, for instance, is reduced by about 300 feet $(28,700$ feet instead of 29,000 feet $)$, and a general reduction in altitude of most of the peaks is apparent. This, however, must not be accepted as a final determination. 'There are other factors in the computation of altitudes observed under extraordinary conditions stil to be determined with more rigorous exactness, and it is quite possible that the ultimate altitude of the highest mountain in the world may be fixed at a higher figure than 29,000 feet rather than a lower one.

A short statement of the progress of topographical surveys in Sind (with no narrative of any interest) and of riverain surveys in the Punjab, with a few notes on town and municipal surveys generally, completes the report.

\section{THE NEEDS OF THE UNIVERSITY OF CAMBRIDGE.}

TEN years ago the Duke of Devonshire, as Chancellor of the University of Cambridge, directed attention to the resources and the needs of the University, and at the beginning of 1899 the Cambridge University Association was formed. The progress towards the re-endowment of the University, which it is the object of the association to promote, is described by the Chancellor in a letter of which a copy has been sent to us, and is here summarised.

The sums which the Cambridge University Association has been able to transfer to the University amount in all to about 115,000 . Of this total a considerable portion was allotted by the donors to the building of the new medical school, the school of engineering, the proposed new buildings of the Cavendish Laboratory, the school of agriculture, the museum of archæology and ethnology, and to the University library, but a large proportion has been available for general purposes.

Although the progress already made in the equipment of the several departments must be regarded with satisfaction, few of the other wants keenly felt in 1899 have yet been met, and in certain cases new wants have inevitably arisen during the last seven years. In the scientific departments every year must of necessity bring new demands for specialisation in teaching and for the provision of facilities for research. In some departments, notably those of agriculture, engineering, and chemistry, the number of students has greatly increased, and additional accommodation is required.

The greater of the immediate needs of the University may thus be stated. The sum of $18,000 l$. promised for the University library represents only the first instalment of a capital sum of $148,000 l$. required. Chemistry requires ro,oool. capital and 2000l. income; physics, 12,000l. capital and at least rool. income; engineering, ro,oool. capital, and income and equipment for research; botany, roool. capital and 25ol. income; physiology, 10,00ol. capital and $1800 l$. income; agriculture, 20,000l. capital (of which $\mathrm{i} 2,000 \mathrm{l}$. has been promised) and 6ool. income; the medical school will cost at least $20,000 \mathrm{l}$. to complete, and in No. I947, VOL. 75] addition a considerable sum is needed for the provision of instruments, \&c., and a large income for additions to the teaching staff. Geology asks for $28 \mathrm{col}$. capital and 130ol. income. A new, or at least a greatly enlarged, museum of zoology will shortly become necessary, and an incom? of I 500 l. is also required for this subject. Entomology, a subject of great importance in its relations to forestry and tropical medicine, is in need of ro, 000l. capital. Oriental studies require 2000 . income. A new museum of archæology and ethnology, urgently needed for the preservation, and for the display for the use of researchers, of the valuable collections possessed by the University, will cost $25,000 l$, and a considerable income will be required for staff and maintenance. History is in need of $800 l$. income, and a sum for the provision of lecture rooms. Economics require $2000 l$. income, the moral sciences (including experimental psychology) I $400 l$. capital and $1250 l$. income. Classics require about $900 l$. income, and mathematics capital for new iecture-rooms and $3500 l$. income. Law asks for 6ool. income. Modern languages urgently require a sum sufficient to create professorships in at least English, French, and German (at present represented by two readers and a lecturer), and to ensure the proper representation of other modern languages. There are other needs, soms of them not intrinsically less important than those mentioned, but demanding more modest sums for their satisfaction.

The disabilities arising from the low scale of existing salaries are common to almost every department. The average stipend of a professor is but $55 \mathrm{ol}$., and that of a university teacher, other than a professor, $250 l$. per annum, and these figures include the emoluments received from fellowships and from fees. The disability is increased by the fact that the University can set aside only 200 . per annum to form a pension fund for its forty-four professors, and nothing at all for other teachers. There is, in addition, need for the creation of many new posts.

If the University is to retain the services of its most distinguished men it is imperative that the income assured to them, both during and after the period of active work, should bear comparison with what they may obtain in similar positions elsewhere.

It $1 \mathrm{~s}$ stated that in all a capital sum of nearly one million and a half, apart from any question of a pension fund for professors, might without extravagance be immediately expended on the equipment of, and on the provision of staff for, the University.

\section{UNIVERSITY AND EDUCATIONAL INTELLIGENCE.}

CAmbridge.-The professorship of agriculture in the University was established in the year 1899 , in consequence of a generous offer by the Drapers' Company to contribute $800 l$. a year for ten years to the agricultural education fund, for the stipend of the professor. The Drapers' Company has now signified its intention to continue its contribution of $800 l$. a year for a further period of ten years, dating from the year 1909 , on the understanding that the Department of Agriculture, and the stipend of the professor, shall be maintained as at present. The company has further expressed approval of a suggestion, made by the board of agricultural studies, that the source of the endowment should be indicated, as in the case of some other foundations, by attaching to the chair the title of the "Drapers' Professorship of Agriculture."

The following have been appointed members of the board of electors to certain professorships:-Dr. Keynes and Mr. W. E. Johnson, of King's College, to that of the Knightsbridge professorship of moral philosophy; $\mathrm{Mr}$. F. H. Neville, of Sidney Sussex College, to that of the professorship of chemistry and to that of the Jacksonian professorship of natural philosophy; Prof. Forsyth, to that of the Plumian professorship of astronomy; Prof. Howard Marsh, to that of the professorship of anatomy; Prof. S. H. Vines, to that of the professorship of botany; Dr. Bonney, to that of the Woodwardian professorship of geology and to that of the professorship of mineralogy; Sir Thomas Barlow, Bart., to that of the Downing pro- 